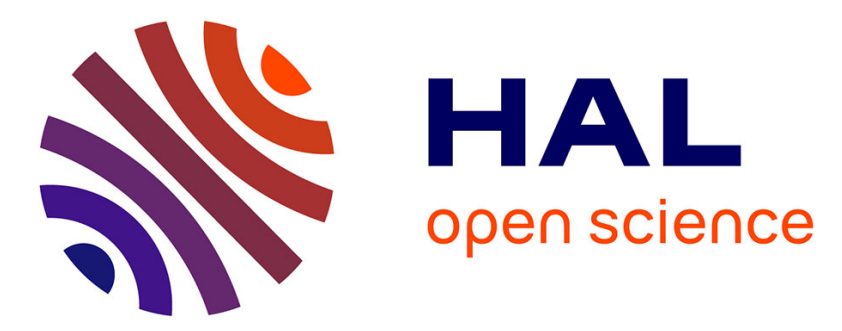

\title{
Percutaneous absorptiometry by UV laser photoacoustic method using a novel open-ended cell combined with light guide
}

\author{
R. Takamoto, S. Yamamoto, R. Namba, M. Matsuoka, T. Sawada
}

\section{- To cite this version:}

R. Takamoto, S. Yamamoto, R. Namba, M. Matsuoka, T. Sawada. Percutaneous absorptiometry by UV laser photoacoustic method using a novel open-ended cell combined with light guide. Journal de Physique IV Proceedings, 1994, 04 (C7), pp.C7-453-C7-456. 10.1051/jp4:19947105 . jpa-00253157

\section{HAL Id: jpa-00253157 https://hal.science/jpa-00253157}

Submitted on 1 Jan 1994

HAL is a multi-disciplinary open access archive for the deposit and dissemination of scientific research documents, whether they are published or not. The documents may come from teaching and research institutions in France or abroad, or from public or private research centers.
L'archive ouverte pluridisciplinaire HAL, est destinée au dépôt et à la diffusion de documents scientifiques de niveau recherche, publiés ou non, émanant des établissements d'enseignement et de recherche français ou étrangers, des laboratoires publics ou privés. 


\title{
Percutaneous absorptiometry by UV laser photoacoustic method using a novel open-ended cell combined with light guide
}

\author{
R. Takamoto, S. Yamamoto, R. Namba, M. Matsuoka and T. Sawada* \\ Safety and Analytical Research Center, Shiseido Company Ltd., 1050 Nippa-cho, Kohoku-ku, \\ Yokohama 223, Japan \\ * Department of Industrial Chemistry, Faculty of Engineering, The University of Tokyo, 7-3-1 Hongo, \\ Bunkyo-ku, Tokyo 113, Japan
}

\begin{abstract}
A UV laser photoacoustic(PA) method with high sensitivity and accuracy using a novel open-ended cell was developed. This PA cell was constructed by processing the end of a light guide as the sample chamber and by attaching an acoustic pipe bent at a right angle. The newly developed PA method is applicable to the study of percutaneous absorption.
\end{abstract}

\section{INTRODUCTION}

Evaluating the percutaneous absorption of a substance is very important for the development of endemic liniments. Therefore, various methods for investigating percutaneous absorptiometry such as the diffusion cell method and radioisotope have been studied. However, a method capable of reliably and easily measuring percutaneous absorption has not yet been developed. In particular, it is very difficult to acquire reliable in vivo results.

We have reported the development of percutaneous absorptiometry using the laser PA method and its usefulness in in vitro and in vivo measurements. This system combined with a longitudinal diffusion cell was generally used for in vitro percutaneous absorptiometry to substantiate its applicability for in vitro measurement ${ }^{1}$ ). It was actually applied to human in vivo percutaneous absorptiometry to demonstrate the feasibility of this method ${ }^{2}$. By measuring the change in the PA signal in time corresponding to the amount of drug remaining on the skin, we were able to evaluate the percutaneous absorption of drugs. In order to extend the range of compounds that can be tested by this method, we have developed a new UV laser PA method with high sensitivity and accuracy using the concept of a novel open-ended PA cell ${ }^{3}$ ). In developing this PA cell, the influence of skin surface potential and environmental noise (less than $100 \mathrm{~Hz}$ ) was minimized. Furthermore, the dead volume of the PA cell and the cell were minimized.

A series of percutaneous absorptiometries using the new open-ended PA cell were performed. The feasibility of the percutaneous absorptiometry technique utilizing this PA method are reported.

\section{EXPERIMENTAL}

Figure 1 shows the construction of the novel open-ended PA cell incorporating the light guide. A bundle-type guide (Asahi Glass Corp., $5 \mathrm{~mm}$ diameter $\mathrm{x} 1 \mathrm{~m}$ ), that transmits more than $85 \%$ of the UV light, was used to provide more flexibility of measurement and to minimize the dead volume in the cell. The open-ended PA cell was constructed by using the end section of the light guide as the sample chamber (stainless steel) and by attaching an acoustic pipe ( $\beta$-brass; bent at a right angle) inside the end of the light guide. A microphone (Primo, MP-10) was threaded to the acoustic pipe in order to control the length of the acoustic pipe. The volume and width of the air layer in the sample chamber are $0.04 \mathrm{~cm}^{3}$ and 0.2 $\mathrm{cm}$, respectively. The total length of the acoustic pipe connecting the sample chamber and the microphone chamber is $8 \mathrm{~cm}$. These dimensions were found to produce a resonance at a frequency of several kilohertz 


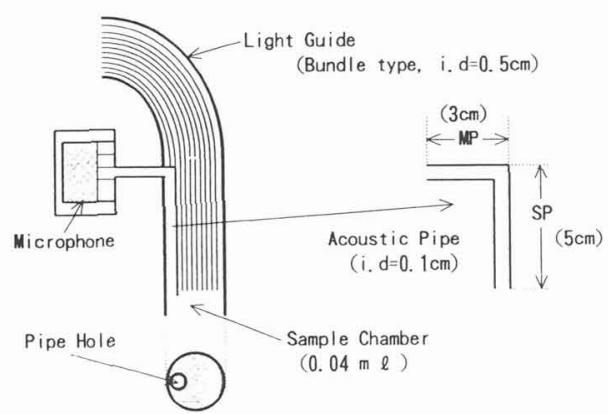

Fig. 1 Diagram of a novel open-ended PA cell combined with the light guide.

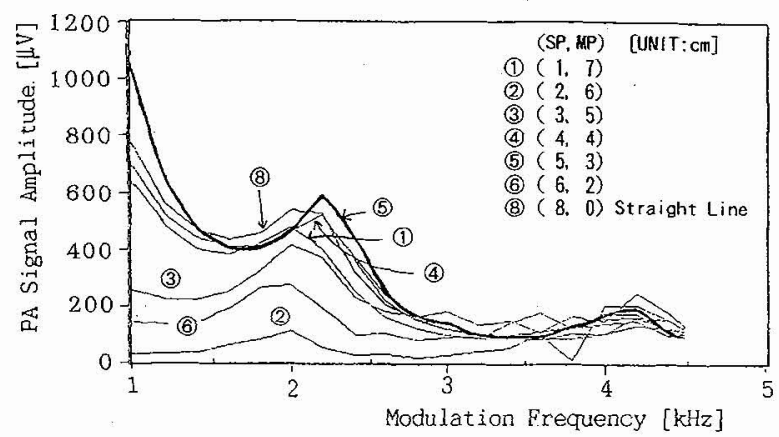

Fig. 2 A comparison of the PA signal amplitude with changes in the length of (SP) and (HP). $(S P+M P=8 \mathrm{~cm})$

that was hardly influenced by pulsation from the skin and by environmental noise. This resonance frequency, $f$, of an open-pipe resonance can be calculated from the equation

$$
\mathrm{f}=\mathrm{m}(\mathrm{c} / 2 \mathrm{~L}) \text {, }
$$

where $m$ is an integer, $c$ is the actual speed of sound, and $L$ is the total length of the acoustic pipe( $f$ can be adjusted by changing the length of the acoustic pipe). The acoustic pipe was bent at a right angle(sides 5 $\mathrm{cm}$ and $3 \mathrm{~cm}$ ) as shown in Figure 1; these lengths were chosen based on the results shown in Figure 2. It shows the frequency characteristics of the PA signal when changing position of the bending point(SP) of the acoustic pipe (total length is $8 \mathrm{~cm}$ ). When the " $\mathrm{f}$ "resonance frequency is kept constant (about 2.2 $\mathrm{kHz}$ ), the PA signal amplitude is largest when SP is $5 \mathrm{~cm}$. The changes in the PA signal amplitude as a result of changes in the length of SP seem to be caused by a very complex interaction(such as the relationship between the wavelength (16 cm at room temperature) at a frequency of $2.2 \mathrm{kHz}$ and the reflection of sound by the bend in the acoustic pipe). We determined a PA cell structure for producing a resonance effect much greater than that of the previously reported2) PA cell (SP=8).

Figure 3 shows a system for in vivo percutaneous absorptiometry. It uses an open-ended PA cell combined with the light guide. UV light $(257 \mathrm{~nm})$ was used as a radiation source and was obtained from a multiple $\mathrm{Ar}^{+}$laser beam (Spectra Physics, Model-2020) at $5 \mathrm{~W}$ and a $\mathrm{BBO}\left(\mathrm{\beta}-\mathrm{BaB}_{2} \mathrm{O}_{4}\right)$ crystal wavelength converter (Ascal Corp.,UVA-4), that can be optically micro-adjusted. The UV laser beam was modulated at $2.2 \mathrm{kHz}$ (resonance frequency of the PA cell) using a light chopper (NF Corp.). The output intensity of the light source was set to $3 \mathrm{~mW}$ by the light guide. The PA signal was processed using a lock-in amplifier (NF Corp. 5610A) and recorded using a chart recorder (Rika Denki Kogyo, NP-0393) and calculated using a computer (Nippon Denki Corp., VX).

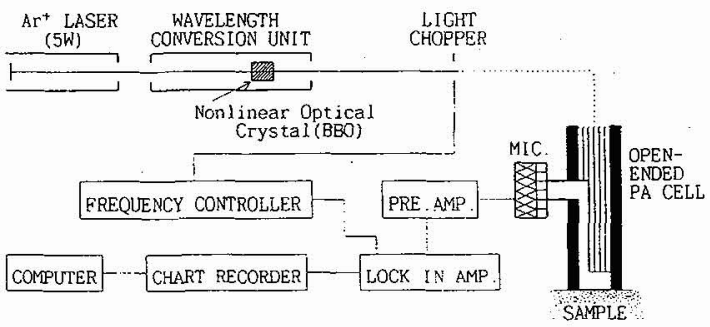

Fig. 3 Diagram of the UV laser PA method using a novel open-ended PA cell combined with the light guide.

\section{RESULTS AND DISCUSSION}

\subsection{Sensitivity and Reproducibility of a Novel Open-ended PA cell}

The sensitivity of the newly-developed PA cell was studied by comparing its performance to that of a conventional PA cell ${ }^{2}$ ). Black rubber was used as the sample. The $\mathrm{Ar}^{+}$laser beam (wavelength $488 \mathrm{~nm}$ ) used as a light source was modulated at $2.2 \mathrm{kHz}$ and the output intensity of the light source was adjusted to $3 \mathrm{~mW}$. The PA signals of the new cell at a specific frequency were compared to those of the conventional PA cell2). As shown in Figure 4, two resonance peaks were found (at about $2.2 \mathrm{kHz}$ and $4.0 \mathrm{kHz}$ ). The intensities of these peaks were about 7 and 26 times larger than those observed using the conventional PA cell. From these results, the estimated sensitivity of the new PA cell is approximately 10 times better than that of the conventional PA cell2). The accuracy of the PA measurement was investigated 


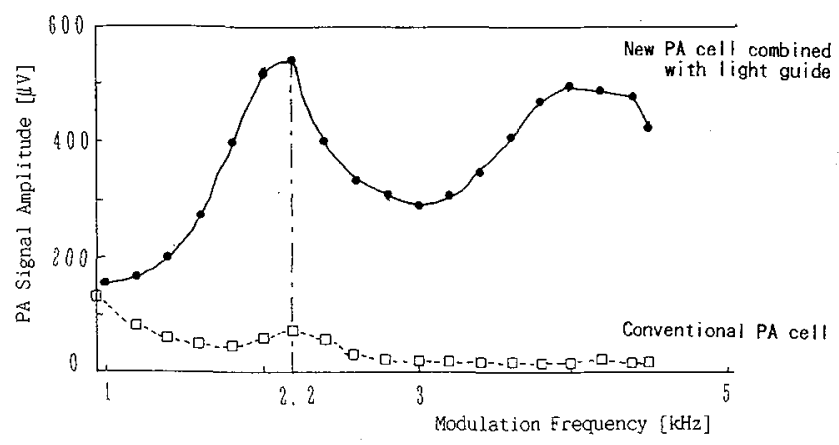

Fig. 4 Sensitivity of the newly developed PA cell compared to that of the conventional PA cell.

using a UV laser PA system and indomethacin(IDM) ointments (vehicle; polyethylene glycol) as a sample. Excellent sensitivity and reproducibility were obtained for series of 10 measurements of IDM( $4 \mu \mathrm{g} / 5 \mathrm{~mm} \phi)$; the $\mathrm{S} / \mathrm{N}$ was 46 and the coefficient of variation(CV) was not more than $3 \%$. An excellent linearity was obtained within the 2-120 $\mu \mathrm{g}$ range of IDM with a correlation coefficient better than 0.99 .

\subsection{Application to the Measurement of Percutaneous Absorption}

In vitro percutaneous absorptiometry for simultaneously measuring the PA signal and absorbance was developed ${ }^{1)}$ and applied directly to the skin of a hairless mouse. In this experiment, both a decrease in the PA signal and an increase in UV absorbance were simultaneously observed with penetration of IDM through the skin.

In vivo percutaneous absorptiometry was attempted using $1 \%$ IDM ointment applied to a hairless mouse. Measurements were made every $5 \mathrm{~min}$ utes in order to avoid accelerated percutaneous absorption as a result of heating caused by the UV laser beam. A rapid measurement time of about 15 seconds could be achieved using the improved $\mathrm{S} / \mathrm{N}$. This was very effective in minimizing any damage to the in vivo skin. The obtained $\mathrm{S} / \mathrm{N}$ was about 40. Figure 5 shows the results of five scans. When PA signals obtained with the PEG vehicle are compared to those of the 1\% IDM ointment measured under the same conditions, it was found that the former was nearly constant in time, while the latter showed a 5\% reduction in the initial PA signal after 60 minutes. It was confirmed that the reduction of the PA signal is not due to a chemical change or destruction of IDM by irradiation. The change in the PA signal is thought to reflect the per-

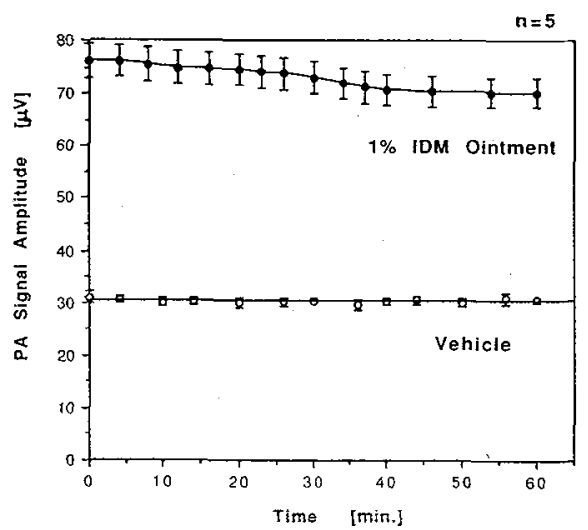

Fig. 5 PA signal versus time in the in vivo percutaneous absorption study of hairless mouse. cutaneous absorption of IDM. We then tried to obtain the diffusion coefficient of IDM across the skin of a hairless mouse in vivo by observing the time constant of decreasing PA signal4). Since a decrease in the concentration of IDM was essentially exponential, the time constant was obtained by plotting logarithmic PA signals versus time. In addition, from the theory of diffusion of substances across membranes of a finite width, it was found that the time constant, $\tau$, of such processes can be expressed as

$$
\tau=4 \mathrm{~L}^{2} / \pi^{2} \mathrm{D}
$$

where $\mathrm{L}$ is the width of a membrane and $\mathrm{D}$ is the diffusion coefficient of the substance in a given medium. This principle was applied to results in Figure 5 . A time constant of 607 minutes was obtained with a correlation coefficient of 0.948 ; the diffusion coefficient was calculated to be $6.7 \times 10^{-6} \mathrm{~cm}^{2} / \mathrm{min}$ for a 0.1 $\mathrm{cm}$ thick skin. This value is on the same order $\left(3.5 \times 10^{-6} \mathrm{~cm}^{2} / \mathrm{min}\right)$ of magnitude as that obtained by the conventional in vitro method using a longitudinal diffusion cell. These results confirmed the effectiveness 
of this newly-developed in vivo percutaneous absorptiometry technique that is simpler than other methods (such as using a radioisotope).

Next, an in vivo study of percutaneous absorption in a guinea pig was performed using a $0.8 \%$ picolinic zinc (PZ) solution (vehicle: water $60 \%+$ glycerin $40 \%$ ).

As shown in Figure 6, anticipated differences between normal skin and stripped skin during the percutaneous absorption of $\mathrm{PZ}$ were obtained by this novel technique.

\section{CONCLUSIONS}

A novel system for in vivo percutaneous absorptiometry using an open-ended PA cell combined with a light guide was developed. The sensitivity of this system was nearly one order of magnitude better than that of the conventional open-ended PA cell 2 ). This system is capable of measuring the

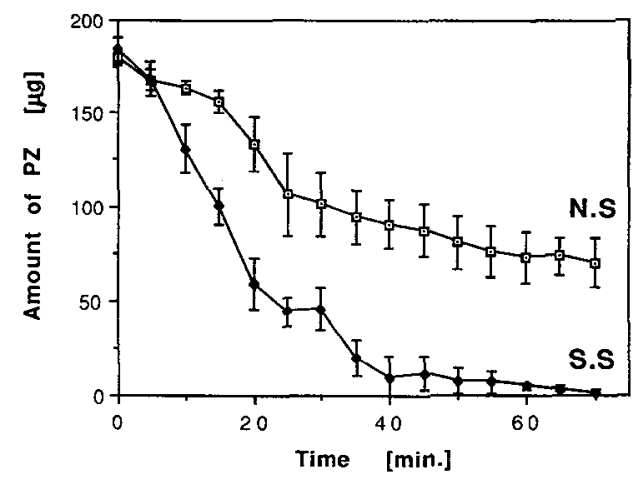

Fig. 6 In vivo percutaneous absorption of a normal skin(N.S) compared to that of a stripped skin(S. S). in vivo reduction of a drug above the skin at any optional site with great ease, high sensitivity and accuracy. Based upon the results shown above, it was concluded that the newly developed UV laser PA method in combination with a novel open-ended cell could be applied to the study of percutaneous absorption.

The total energy received by the skin was less than $40 \mathrm{~mJ}$ and no harmful effects were observed on the skin of hairless mice. Applying the same energy levels to specimens of living human skin is thought possible, although a final confirmation has yet to be made. Such experiments are currently underway.

\section{REFERENCES}

1) Takamoto, R. ; Namba, R. ; Nakata, O. ; Sawada, T. Anal. Chem. 62 (1990) 674-677.

2) Takamoto, R. ; Namba, R.; Matsuoka, M. ; Sawada, T. Anal. Chem. 64 (1992) 2661-2663.

3) Takamoto, R.; Yamamoto, S. ; Namba, R. ; Takamatsu, T.; Matsuoka, M. ; Sawada, T. Anal. Chem. , 1993 Submitted for Publication.

4) Steven, D.C. ; Sinclair, S.Y.; Martin, A.A. IEEE Transactions on Biomedical Engineering BME-26(4) (1979), 220-227. 